\title{
Stepping Up to the Plate: An Agenda for Research and Policy Action on Electronic Medical Records in Canadian Primary Healthcare
}

\section{Passer à l'action : programme de recherche et suggestions d'orientation sur les dossiers médicaux électroniques dans les soins de santé primaires au Canada}

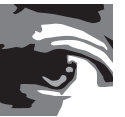

AMANDA L. TERRY, PHD

Assistant Professor, Department of Family Medicine, Department of Epidemiology E Biostatistics

Schulich Interfaculty Program in Public Health

The University of Western Ontario

London, $\mathrm{ON}$

MOIRA STEWART, PHD

Distinguished University Professor

Department of Family Medicine, Department of Epidemiology \& Biostatistics

Schulich School of Medicine E Dentistry

The University of Western Ontario

London, $\mathrm{ON}$

$$
\begin{gathered}
\text { MARTIN FORTIN, MD, MSC, CMFC(F) } \\
\text { Professor, Department of Family Medicine } \\
\text { Université de Sherbrooke } \\
\text { Sherbrooke, QC }
\end{gathered}
$$

SABRINA T. WONG, RN, PHD

Professor, UBC School of Nursing and Centre for Health Services and Policy Research

University of British Columbia

Vancouver, BC

INESE GRAVA-GUBINS, MA

Research Consultant

Toronto, ON 
Amanda L. Terry et al.

LISA ASHLEY, RN, CCHN(C), MED

Senior Nurse Advisor, Canadian Nurses Association

Academic Consultant Level 2, School of Nursing

University of Ottawa

Ottawa, ON

PATRICIA SULLIVAN-TAYLOR, BSCN, MPA, PMP

Director, Health System Funding Policy

Ontario Ministry of Health and Long-Term Care

Toronto, ON

FRANK SULLIVAN, FRSE, FRCP, FRCGP, CCFP

Gordon F. Cheesbrough Research Chair and Director of UTOPIAN,

Professor, Department of Family E Community Medicine

Dalla Lana School of Public Health

University of Toronto

Toronto, ON

LYNNE ZUCKER, BASC, MASC

Vice President, Clinical Systems Integration, Canada Health Infoway

Toronto, ON

AMARDEEP THIND, MD, PHD

Professor, Department of Family Medicine, Department of Epidemiology E Biostatistics

Director, Schulich Interfaculty Program in Public Health

The University of Western Ontario

London, $\mathrm{ON}$

\begin{abstract}
Building on a previous study, which identified gaps in primary healthcare electronic medical record (EMR) research and knowledge, a one-day conference was held to facilitate a strategic discussion of these issues. This paper offers a multi-faceted research agenda and suggestions for policy actions as a way forward in bridging the gaps. One facet focuses on the need for research. The second facet focuses on harnessing the knowledge of primary healthcare EMR stakeholders. Finally, the third facet focuses on policy actions. This paper offers consensus-based suggestions with a view to improving the overall primary healthcare EMR landscape in Canada.
\end{abstract}

\title{
Résumé
}

En réponse à une première étude qui identifiait des lacunes dans la recherche et les connaissances concernant les dossiers médicaux électroniques (DME) dans les soins de santé primaires, une conférence a eu lieu afin de permettre une discussion stratégique sur cette situation. Cet article présente un programme de recherche multifacette et des suggestions d'orientation afin de combler ces lacunes. La première facette souligne le besoin de faire de la recherche. La seconde facette porte sur la canalisation des connaissances des parties prenantes liées aux DME dans les soins de santé primaires. Finalement, le troisième aspect soulève 
des suggestions d'orientation. Cet article présente un consensus sur la manière d'améliorer le portrait global des DME dans les soins de santé au Canada.

\section{Introduction}

Electronic medical records (EMRs) have the potential to be a transformational force in both primary healthcare research (PHC) and practice in Canada (Birtwhistle and Williamson 2015; Report of the Advisory Panel on Healthcare Innovation 2015). Despite mixed evidence regarding the impact of EMRs on clinical practice (Lau et al. 2012), levels of adoption continue to grow across Canada (Chang and Gupta 2015; College of Family Physicians of Canada et al. 2014; Schoen et al. 2012). Variability exists among provinces, however, with areas of lower physician EMR use (e.g., Newfoundland and Labrador) and areas with higher use (e.g., Alberta) (Chang and Gupta 2015). Positive signs include clinicians perceiving a benefit from EMRs (Bassi et al. 2012), particularly with increasing experience in their use and when the EMR supports advanced use (King et al. 2014). Benefits to be gained from EMR use are likely dependent upon the use of fully functional systems that are integrated into practice (Friedberg et al. 2009). Yet there is a small amount of research evidence, particularly in the Canadian context, to support this integration.

Given this reality, we conducted a pan-Canadian study, which identified 12 key gaps in research and knowledge facing PHC EMR stakeholders (Terry et al. 2014). Other work in the Canadian context has identified the need for research focused on EMR adoption and for initiatives that would aid advanced EMR use (Canada Health Infoway 2013; CMA 2015; Price et al. 2013; Rimmer et al. 2015). This prompts the question of how to bridge these gaps from both a policy and research perspective. Building on the findings of this initial study, this paper provides a strategic discussion of the identified gaps and identifies a way forward.

\section{Methods}

To facilitate this discussion, we held a one-day conference in Toronto, Canada (March 2012) in partnership with the Canadian Institute for Health Information (CIHI 2012). Prior to the conference, participants received an information package, which outlined the 12 gaps in EMR research and knowledge; participants were asked to self-select their preferred topic to discuss during small group discussions. We reviewed these selections, as well as those chosen by conference participants at the beginning of the day, and identified seven gaps of the original 12 , which the majority of participants wanted to discuss. The small groups were guided by a facilitator; notes were recorded by a designated group member on a template that was provided to them.

Over 100 conference participants chose to discuss seven gaps in EMR research and knowledge (value of EMRs, EMR implementation and adoption, data entry and extraction procedures, data sharing, overarching framework for interoperability, define data elements 
and develop an ideal EMR design). In the following, we discuss how the ideas generated by participants might be addressed through research or policy initiatives. Though the conference occurred in 2012, the issues identified remain salient today (Canada Health Infoway 2013; CMA 2015; Pare et al. 2014; Price et al. 2013; Report of the Advisory Panel on Healthcare Innovation 2015; Rich 2015). Given that overall PHC EMR adoption in Canada has greatly advanced since 2012, some of the gaps discussed at the conference, such as EMR implementation and adoption, would be more relevant in parts of Canada where adoption rates are lower. Other gaps, including data sharing, may be more of a concern in areas where EMR adoption has occurred over a longer period of time and where levels of use are higher.

\section{Conference Findings}

The findings from each topic group are presented, followed immediately by a discussion regarding how the gap might be addressed through research or policy initiatives (Table 1).

TABLE 1. Summary of actions to address knowledge and research gaps

\begin{tabular}{|c|c|}
\hline Gap in knowledge and research & Summary of action points \\
\hline I. Value of EMRs & $\begin{array}{l}\text { - Explore connection between maturity of use and accrued value } \\
\text { - Understand trade-off: effort of adoption versus value } \\
\text { - Create a value map/matrix (stakeholders on one axis, value EMR brings on other axis) }\end{array}$ \\
\hline 2. EMR implementation and adoption & $\begin{array}{l}\text { - Supply basic and advanced training, support and education for users } \\
\text { - Understand value of implementation and adoption } \\
\text { - Identify non-adopters - identify barriers to adoption and how to overcome them } \\
\text { - Identify best practices of advanced users - success and supports, conduct economic analysis } \\
\text { - Synthesize existing data and research reports }\end{array}$ \\
\hline 3. Data entry and extraction procedures & $\begin{array}{l}\text { - Create unified standards and capabilities across EMRs } \\
\text { - Deliver incentives for data quality } \\
\text { - Use improved data search technology } \\
\text { - Test data entry interventions } \\
\text { - Understand best practices leading to high optimization and data entry }\end{array}$ \\
\hline 4. Data sharing & $\begin{array}{l}\text { - Define standardized data sets and determine sharing rules } \\
\text { - Work towards interprovincial consistency } \\
\text { - Understand public attitudes }\end{array}$ \\
\hline $\begin{array}{l}\text { 5. Overarching framework for } \\
\text { interoperability }\end{array}$ & $\begin{array}{l}\text { - Implement overarching framework across Canada } \\
\text { - Create a communication strategy for framework }\end{array}$ \\
\hline 6. Define data elements & $\begin{array}{l}\text { - Expand data collected in EMR, e.g., quality of life } \\
\text { - Include data elements from different sources, e.g., patients } \\
\text { - Design a data completeness score function }\end{array}$ \\
\hline 7. Develop ideal EMR design & $\begin{array}{l}\text { - } \text { Design needs to match PHC context } \\
\text { - Include multiple disciplines } \\
\text { - Research - inform existing and new EMR designs }\end{array}$ \\
\hline
\end{tabular}

$\mathrm{EMR}=$ electronic medical record; $\mathrm{PHC}=$ primary healthcare research.

\section{Value of EMRs - findings}

This theme focused on the value proposition of EMRs for a broad group of stakeholders, including clinicians, decision-makers and health system planners. Within this theme, participants offered three ideas for how to address this issue. The first was to explore the 
connection between practitioners' maturity of EMR use (for example, level of use of elements of the EMR, participation in peer-to-peer support networks) and the value that the practitioner accrued from the EMR. The second was to understand the possible trade-offs between the effort or cost of adoption and the value realized. Participants suggested there may be a point of diminishing returns in terms of EMR use, and they wanted to promote research that would search out when and where this might occur. The third idea was to create a value map or a matrix on which the stakeholders would be represented on one axis, while the type of value the EMR could bring to them (e.g., financial, satisfaction) would be noted on the other axis. This matrix would illustrate the type of value associated with EMR use that would apply to each stakeholder.

\section{Value of EMRs - author discussion}

Participants' suggestions of exploring the connection between maturity of use and accrued value, as well as the trade-off between effort of adoption and value, could be realized through health economics studies. Creating a value map should be completed by harnessing the input of primary healthcare EMR stakeholders in Canada. There is existing work in Canada regarding frameworks to assess the value of e-Health (Lau et al. 2014), EMR value (Canada Health Infoway 2013; Rubinowicz et al. 2016) and return on investment (Jang et al. 2014); other broader economic analyses and frameworks exist elsewhere in the literature (Bassi and Lau 2013; Payne et al. 2013). Despite mixed evidence of EMR effects on practice, we do know that the likelihood of positive impact is dependent upon optimal EMR use (Friedberg et al. 2009) and successful integration into workflow (Jang et al. 2014). Therefore, the next step in realizing the full value of EMRs is to better understand how to achieve optimal use by building on existing work focused on EMR optimization in Canada (CMA 2015; Price et al. 2013; Raymond et al. 2015), elsewhere (Ornstein et al. 2015; Pandhi et al. 2014) and the use of specific tools within the EMR such as electronic prescribing (e-prescribing) (Motulsky et al. 2013; Randhawa et al. 2013). The knowledge gained from this research should then be scaled up more broadly across the PHC setting to enable practitioners to advance their EMR use and to realize the potential full value of EMRs.

\section{EMR implementation and adoption - findings}

The main concept of this theme revolved around determining how and why primary healthcare practitioners are adopting or not adopting EMRs into practice. Participants offered a number of options for moving forward. On the policy side, a need to support basic EMR implementation was identified, as well as more advanced training, support and education for EMR users. Funding and incentives to facilitate implementation and adoption were also cited as examples of such support that would fall within the policy domain. From a research perspective, there were four areas that participants pinpointed: (1) understanding the value of EMRs from a patient outcome, financial, productivity and efficiency perspective; (2) seeking out EMR non-adopters to understand the barriers to adoption and how to overcome them; (3) analyzing best practices 
of existing successful EMR users over time, identifying the policies and procedures that support this type of use and conducting an economic analysis based on successful users; and (4) using existing data and research reports on implementation and adoption to inform this topic.

\section{EMR implementation and adoption - author discussion}

Addressing issues of EMR implementation and adoption would benefit from a series of studies focused on successful EMR users and those who do not use EMRs at all, as well as research synthesizing current information on this topic in Canada (Archer and Cocosila 2011; Greiver et al. 2011b; Lai et al. 2009; McGinn et al. 2012; Pare et al. 2014; Paterson et al. 2011; Price et al. 2013; Terry et al. 2009; Vedel et al. 2012) and elsewhere (Boonstra and Broekhuis 2010; Castillo et al. 2010; McGinn et al. 2011). Further work could be done on identifying the policy levers that best support EMR implementation and adoption. While barriers and facilitators to EMR implementation and adoption have been identified (Archer and Cocosila 2011; Boonstra and Broekhuis 2010; Castillo et al. 2010; Greiver et al. 2011b; Lai et al. 2009; McGinn et al. 2012, 2011; Pare et al. 2014; Paterson et al. 2011; Price et al. 2013; Terry et al. 2009; Vedel et al. 2012), this issue remains prominent in the EMR landscape in Canada, including consideration of longer-term adoption issues (Green et al. 2015; Terry et al. 2012). Recent work has identified exemplars of successful health information technology adoption (Jones and Wittie 2015; McAlearney et al. 2010; Ornstein et al. 2015; Ryan et al. 2014), provided guidance for the adoption of information technology at a broader level (Cresswell et al. 2013) and explored the adoption of e-prescribing in primary care (Sicotte et al. 2013). Best practices in implementation and adoption need to be explored and summarized, particularly as they relate to PHC EMRs. In addition, the structures supporting the application of these best practices in the PHC setting should be determined. These findings, when translated into supports and structures at the level of the healthcare system and the practice, would enable comprehensive implementation and adoption across Canadian PHC.

\section{Data entry and extraction procedures - findings}

This theme was centred on how to get data into the EMR, and how to get it out of the EMR, in the best possible way. A combined research and policy strategy discussed was to examine EMR vendor-specific structural differences across jurisdictions. This could be done with a view to creating unified capacity and mandated content standards to support high-quality data entry and extraction. From the policy perspective, participants thought it was important to have practitioner incentives in place to support the goal of complete and accurate data on specific topics such as preventive care tests. Three areas were identified that required further research: (1) technologies to search EMR data regardless of how the data were entered; (2) intervention programs for practitioners focused on data entry, which would consist of feedback and a peerto-peer training approach; (3) best practices that lead to high optimization and data quality levels. Within these strategies, participants emphasized the need to strike a balance between the resources that would be required to support data entry and its ultimate usability. 


\section{Data entry and extraction procedures - author discussion}

Recommended steps to address this gap include: (1) conducting a literature review to identify best practices leading to optimal use and data quality from other settings that are potentially transferable to PHC; and holding a series of policy dialogues focused on unified EMR capacity, implementation of rigorous content standards and priorities for EMR data entry supports. This would build on existing best practices, for example, in system design (Horsky et al. 2012) and the work of CIHI in developing and disseminating the "PanCanadian PHC Electronic Medical Record Content Standards" (CIHI 2012). Research in this area could focus on identifying existing and emerging data searching technologies to be tested in different EMRs in the PHC setting. Trials could be conducted to build on existing work and to test interventions focused on optimal data entry (Brouwer et al. 2006; Greiver et al. 2011a, 2015).

A problem central to this issue is the reality that different stakeholders often have different reasons for their interest in data entry and extraction. PHC practitioners may be interested because they want to be able to treat and track individual patients over time and examine their practice populations as a whole. Policy makers may be interested in the potential to have access to standardized PHC data for planning health system change. Researchers need high-quality PHC data for their studies. Vendors are concerned due to potential future requirements for EMR designs. The next step, therefore, is to understand these perspectives more thoroughly, prior to embarking on research or policy action. Identifying shared areas of focus and priority for most stakeholders would be a logical starting place for these actions.

\section{Data sharing - findings}

This theme reflects existing uncertainty about how EMR data can be shared, with whom, under what circumstances and for what purpose. There were three main strategies identified by participants regarding data sharing. The first two of these are policy-related: (1) define standardized data sets, and determine who should share them and under what circumstances they could be shared. Conference attendees thought that patients, policy makers and practitioners should all be engaged in this work; (2) work towards achieving interprovincial consistency in data sharing. The final strategy was research-related - polling the public regarding their attitudes and opinions about healthcare data sharing.

\section{Data sharing - author discussion}

A necessary precursor to work on defining data sets and working towards interprovincial consistency is the need to more fully understand the views of patients regarding data sharing, particularly in terms of EMRs in PHC. Studies in the Canadian context have examined the perspectives of individuals about health information privacy and the circumstances under which data may be shared (Perera et al. 2011; Willison et al. 2003, 2007, 2009), and Canada Health Infoway has offered guidance on information governance in relation to interoperable electronic health records (EHRs) (Canada Health Infoway 2007). Canadian opinion polls 
also exist, which have explored broader questions of privacy, protection of personal information and security and safety of personal health information (Angus Reid Public Opinion 2013; Ipsos Reid 2012; Phoenix Strategic Perspectives Inc. 2013). Given that the availability of data in electronic form will continue to grow and much uncertainty remains about data sharing, more clarity around this issue is required. This work is critically important as optimal EMR use depends, in part, upon information flows among providers (Friedberg et al. 2009). We know that in Canada, among adopters of EMRs in general (Schoen et al. 2012), and e-prescribing in particular, this is already a challenge (Motulsky et al. 2015). Therefore, a next step would be to conduct a review of the literature, which would summarize the state of current knowledge regarding patient views of data sharing and identify any remaining gaps for which further research is required. This improved understanding of the issues would inform a pan-Canadian effort towards achieving policy- and practice-level consistency, which is required to move forward.

\section{Overarching framework for interoperability - findings}

This theme focuses on interoperability or data flows among practitioners, parts of the healthcare system and among software types. Participants emphasized the need for an overarching framework in Canada, which could ensure interoperability. The framework should include elements relating to governance, infrastructure, privacy, the value of the data, implementation and technology. Furthermore, it was considered important to develop a communication strategy pertaining to the overarching framework and to leverage national bodies such as the College of Family Physicians of Canada to drive action forward on this topic.

\section{Overarching framework for interoperability - author discussion}

The complexity of creating an overarching framework for interoperability necessitates a multi-jurisdictional policy-related initiative; this could potentially build on models such as interoperability-defining use cases (Sittig and Wright 2015). This policy work will require strong links among those who set EMR standards, EMR vendors, patients, healthcare practitioners and other policy makers. Widespread adoption of CIHI's "Pan-Canadian Primary Health Care Electronic Medical Record Content Standards" is a necessary first step to the interoperability question. Canada Health Infoway coordinates pan-Canadian work on digital health standards and recently released the Clinical Interoperability Action Plan to foster collaboration on this issue. Much more remains to be done. Building upon this solid, already existing work, a pan-Canadian policy initiative is necessary to continue the work required towards achieving provincial implementation solutions for this issue.

\section{Define data elements - findings}

This theme was focused on primary healthcare practitioners defining the actual data elements in the EMR that would be needed for patient care and on researchers and policy makers suggesting what would be needed to answer questions about primary healthcare. 
Suggestions made by conference participants regarding defining data elements were policyoriented: (1) include data in the EMR on the illness, not only the diagnoses, such as the patient's personal experience, health history, social determinants of health, death and quality of life; (2) include data elements such as those held by specialists, patients and what might be found in other data repositories; (3) build in a standard data element into each EMR which could calculate a "data completeness score."

\section{Define data elements - author discussion}

As the adoption of EMRs matures, questions about how to make these data even richer have arisen. A pre-requisite to ultimately deciding what might be included in an EMR would be a consensus list of prioritized data elements. The list could be developed by building upon existing work, such as the Institute of Medicine's EHR measures for social and behavioural determinants of health (Adler and Stead 2015). A consensus could be achieved through a Delphi process with Canadian PHC EMR stakeholders. This would enable policy-related steps to be taken, linked with existing work on content standards, and would facilitate discussions with EMR vendors regarding the consistency of data element inclusion. The development and testing of a data completeness scoring system should be undertaken within multiple EMRs. If testing was successful, such a system could be implemented in all EMRs for practitioner use. Thus, a next step would be to initiate two studies - one to create a consensus on data elements and the second to develop and test a data completeness scoring system that could be used by practitioners for self-assessment.

\section{Develop an ideal EMR design - findings}

Conference participants thought that EMRs should be designed to be reflective of the evolving interdisciplinary and team-based nature of primary healthcare. Additionally, it was suggested that individuals who may not usually be present for discussions of EMR design in primary healthcare, such as software engineers and pharmacists, should be included. In the research domain, participants thought it was important to build on the research that already exists in terms of EMR design in primary healthcare but that more research was needed specific to the Canadian context. This research should involve observing what is happening in primary healthcare practices to help inform ideal EMR design.

\section{Develop an ideal EMR design - author discussion}

An interdisciplinary network, where ideas to support EMR design could be exchanged and fostered with focused dialogues, could help address gaps in EMR design. This network would harness the existing research-based knowledge, as well as facilitate the emergence of new ideas, building on existing work examining EHR functionality in primary care (Krist et al. 2014). The group would also coordinate collaborative research ventures focused on informing ideal EMR design. There are existing networks across Canada, such as the Canadian Primary Care Sentinel Surveillance Network, eHealth Benefits Evaluation Knowledge Translation 
Community and the National Institutes of Health Informatics, which could inform this work. An important aspect of EMR design is the concept of the computer as a third party in the encounter (Pearce et al. 2011). A further dimension of EMR design should be focused on the organizational dimension of PHC practice - how does the EMR integrate into the functions of the practice (Beasley et al. 2011; Unertl et al. 2009)? Development of a multidisciplinary network of individuals across Canada interested in EMR design is an important next step.

\section{Limitations}

The following limitations of these discussions are noted. For some topics, there were clearly identified areas where more research was needed, whereas in others, it was more self-evident that policy-related actions needed to occur. There were also some grey areas in which the two facets of research and policy intertwined for particular issues, such as data entry and extraction. In addition, although patient-specific gaps were not discussed, it should be acknowledged that the patient perspective is a foundational element that underpins all of these issues.

\section{Summary and Conclusions}

Synthesizing the results of the topic group discussions, this paper offers a multi-faceted research agenda and suggestions for policy actions as a way forward in bridging the gaps in PHC EMR knowledge and research in Canada. One facet focuses on the need for research in this area. The second facet focuses on harnessing the knowledge of PHC EMR stakeholders together into a network. Finally, the third facet focuses on EMR-related policy actions.

These facets obviously intertwine, with a network of PHC EMR stakeholders being involved with both the research agenda and policy actions. Finally, we suggest that Canada needs to further develop its capacity to conduct EMR research and to tackle policy-relevant PHC EMR issues. This paper offers consensus-based suggestions with a view to improving the overall PHC EMR landscape in Canada.

\section{Acknowledgements}

The authors thank the conference attendees. This study was funded by the Canadian Institutes of Health Research (CIHR) (\#239664). Dr. Stewart is funded by the Dr. Brian W. Gilbert Canada Research Chair in Primary Health Care Research. Dr. Fortin holds a Chair in Chronic Diseases in Primary Care. Dr. Thind is a Canada Research Chair in Health Services Research. The authors acknowledge the contributions of Francis Lau to the conference and this paper.

Correspondence may be directed to: Amanda L. Terry, PhD, Assistant Professor, Schulich School of Medicine E Dentistry, The University of Western Ontario, Western Centre for Public Health and Family Medicine, 1151 Richmond Street, London, ON N6A 3K7; tel.: 519-661-2111 ext. 20049; e-mail:aterry4@uwo.ca. 


\section{Stepping Up to the Plate}

\section{References}

Adler, N.E. and W.W. Stead. 2015. "Patients in Context-EHR Capture of Social and Behavioral Determinants of Health." New England Journal of Medicine 372 (8): 698-701.

Angus Reid Public Opinion. 2013. Canadians Comfortable with the Public Sector Using Private Data. News Release. Toronto, Ontario, Angus Reid Public Opinion. Retrieved June 6, 2016. <http://angusreidglobal.com/ wp-content/uploads/2008/11/2013.04.08_CityAge.pdf>.

Archer, N. and M. Cocosila. 2011. "A Comparison of Physician Pre-Adoption and Adoption Views on Electronic Health Records in Canadian Medical Practices." Journal of Medical Internet Research 13 (3): e57.

Bassi, J. and F. Lau. 2013. "Measuring Value for Money: A Scoping Review on Economic Evaluation of Health Information Systems." Journal of the American Medical Informatics Association 20 (4): 792-801.

Bassi, J., F. Lau and M. Lesperance. 2012. "Perceived Impact of Electronic Medical Records in Physician Office Practices: A Review of Survey-Based Research." Interactive Journal of Medical Research 1(2): e3.

Beasley, J.W., R.J. Holden and F. Sullivan. 2011. "Electronic Health Records: Research into Design and Implementation." British Journal of General Practice 61(591): 604-05.

Birtwhistle, R. and T. Williamson. 2015. "Primary Care Electronic Medical Records: A New Data Source for Research in Canada." Canadian Medical Association Journal 187(4): 239-40.

Boonstra, A. and M. Broekhuis. 2010. "Barriers to the Acceptance of Electronic Medical Records by Physicians from Systematic Review to Taxonomy and Interventions." BMC Health Services Research 10: 231.

Brouwer, H.J., P.J.E. Bindels and H. Van Weert. 2006. "Data Quality Improvement in General Practice." Family Practice 23: 529-36.

Canada Health Infoway. 2007. "White Paper on the Information Governance of the Interoperable Electronic Health Record.” Retrieved June 6, 2016. <www.ehealthinformation.ca/wp-content/uploads/2014/08/govern. pdf $>$.

Canada Health Infoway. 2013. "The Emerging Benefits of Electronic Medical Record Use in Community-Based Care." Retrieved June 6, 2016. <www.infoway-inforoute.ca/en/component/edocman/resources/reports/benefitsevaluation/1224-the-emerging-benefits-of-electronic-medical-record-use-in-community-based-care-full-report $>$.

Canadian Institute for Health Information (CIHI). 2012. "Implementing Primary Health Care EMR Content Standards Supports Improving Patient Care and Health System Management." Retrieved August 20, 2015. $<w w w . c i h i . c a / e n / e m r \_c s \_e x b e n \_i n f o s h e e t \_e n . p d f>$.

Canadian Medical Association (CMA). 2015. "How Can Canada Achieve Enhanced Use of Electronic Medical Records?” Retrieved June 6, 2016. <www.cma.ca/Assets/assets-library/document/en/advocacy/Enhanced-Useof-EMRs-Discussion-Paper-Final-May-2014.pdf $>$.

Castillo, V.H., A.I Martinez-Garcia and J.R. Pulido. 2010. "A Knowledge-Based Taxonomy of Critical Factors for Adopting Electronic Health Record Systems by Physicians: A Systematic Literature Review." BMC Medical Informatics and Decision Making 10: 60.

Chang, F. and N. Gupta. 2015. "Progress in Electronic Medical Record Adoption in Canada." Canadian Family Physician 61: 1076-84.

College of Family Physicians of Canada, Canadian Medical Association, and Royal College of Physicians and Surgeons of Canada. 2014. "2014 National Physician Survey." Retrieved June 6, 2016. <http://nationalphysiciansurvey.ca/ surveys/2014-survey/>.

Cresswell, K.M., D.W. Bates and A. Sheikh. 2013. “Ten Key Considerations for the Successful Implementation and Adoption of Large-Scale Health Information Technology." Journal of the American Medical Informatics Association 20: e9-e13.

Friedberg, M.W., K.L. Coltin, D.G. Safran, M. Dresser, A.M. Zaslavsky and E.C. Schneider. 2009.

"Associations between Structural Capabilities of Primary Care Practices and Performance on Selected Quality Measures." Annals of Internal Medicine 151 (7): 456-63.

Green, L.A., G. Potworowski, A. Day, R. May-Gentile, D. Vibbert, B. Maki. et al. 2015. “Sustaining 'Meaningful Use' of Health Information Technology in Low-Resource Practices.” Annals of Family Medicine 13(1): 17-22. 
Greiver, M., J. Barnsley, B. Aliarzadeh, P. Krueger, R. Moineddin, D.A. Butt et al. 2011a. “Using a Data Entry Clerk to Improve Data Quality in Primary Care Electronic Medical Records: A Pilot Study." Informatics in Primary Care 19 (4): 241-50.

Greiver, M., J. Barnsley, R.H. Glazier, R. Moineddin and B.J. Harvey. 2011b. "Implementation of Electronic Medical Records: Theory-Informed Qualitative Study." Canadian Family Physician 57: e390-97.

Greiver, M., N. Drummond, R. Birtwhistle, J. Queenan, A. Lambert-Lanning and D. Jackson. 2015. “Using EMRs to Fuel Quality Improvement." Canadian Family Physician 61: 92.

Horsky, J., G.D. Schiff, D. Johnston, L. Mercincavage, D. Bell and B. Middleton. 2012. “Interface Design Principles for Usable Decision Support: A Targeted Review of Best Practices for Clinical Prescribing Interventions." Journal of Biomedical Informatics 45: 1202-16.

Ipsos Reid. 2012. "Electronic Health Information and Privacy Survey 2012: What Canadians Think Toronto: Ipsos Reid." Retrieved June 6, 2016. <www.infoway-inforoute.ca/en/component/edocman/resources/reports/ privacy/461-ipsos-reid-survey-on-electronic-health-information-and-privacy>.

Jang, Y., M.A. Lortie and S. Sanche. 2014. "Return on Investment in Electronic Health Records in Primary Care Practices: A Mixed-Methods Study." JMIR Medical Informatics 2(2): e25.

Jones, E. and M. Wittie. 2015. "Accelerated Adoption of Advanced Health Information Technology in Beacon Community Health Centers." Journal of the American Board of Family Medicine 28: 565-75.

King, J., V. Patel, E.W. Jamoom and M.F. Furukawa. 2014. “Clinical Benefits of Electronic Health Record Use: National Findings." Health Services Research 49(1 Pt2): 392-404.

Krist, A.H., J.W. Beasley, J.C. Crosson, D.C. Kibbe, M.S. Klinkman, C.U. Lehmann et al. 2014. "Electronic Health Record Functionality Needed to Better Support Primary Care." Journal of the American Medical Informatics Association 21 (5): 764-71.

Lai, J.K., F. Lau and N. Shaw. 2009. "A Study of Information Technology Use and Implementation of Electronic Medical Record Systems in BC Medical Practices." BC Medical Journal 51(3): 114-21.

Lau, F., M. Price and J. Bassi. 2014. “Toward A Coordinated EHR Strategy for Canada - A White Paper." Toronto, ON: Queen's School of Business, The Monieson Centre for Business Research in Healthcare. Retrieved June 6, 2016. <https://smith.queensu.ca/centres/monieson/knowledge_articles/toward-acoordinated-electronic-health-record-ehr-strategy-for-canada.php $>$.

Lau, F., M. Price, J. Boyd, C. Partridge, H. Bell and R. Raworth. 2012. "Impact of Electronic Medical Record on Physician Practice in Office Settings: A Systematic Review." BMC Medical Informatics and Decision Making 12: 10.

McAlearney, A.S., P.H. Song, J. Robbins, A. Hirsch, M. Jorina, N. Kowalczyk et al. 2010. "Moving from Good to Great in Ambulatory Electronic Health Record Implementation." Journal of Healthcare Quality 32(5): 41-50.

McGinn, C.A., M.P. Gagnon, N. Shaw, C. Sicotte, L. Mathieu, Y. Leduc et al. 2012. “Users' Perspectives of Key Factors to Implementing Electronic Health Records in Canada: A Delphi Study." BMC Medical Informatics and Decision Making 12: 105.

McGinn, C.A., S. Grenier, J. Duplantie, N. Shaw, C. Sicotte, L. Mathieu et al. 2011. “Comparison of User Groups' Perspectives of Barriers and Facilitators to Implementing Electronic Health Records: A Systematic Review." BMC Medicine 9: 46.

Motulsky, A., L. Lamothe and C. Sicotte. 2013. "Impacts of Second-Generation Electronic Prescriptions on the Medication Management Process in Primary Care: A Systematic Review." International Journal of Medical Informatics 82(6): 473-91.

Motulsky, A., C. Sicotte, M.P. Gagnon, J. Payne-Gagnon, J.A. Langue-Dube, C.M. Rochefort et al. 2015. "Challenges to the Implementation of a Nationwide Electronic Prescribing Network in Primary Care: A Qualitative Study of Users' Perceptions." Journal of the American Medical Informatics Association 22(4): 838-48.

Ornstein, S.M., L.S. Nemeth, P.J. Nieter, R.G. Jenkins, A.M. Wessell and C.B. Litvin. 2015. "Learning from Primary Care Meaningful Use Exemplars." Journal of the American Board of Family Medicine 28(3): 360-70. 


\section{Stepping Up to the Plate}

Pandhi, N., W.L. Yang, Z. Karp, A. Young, J.W. Beasley, S. Kraft et al. 2014. “Approaches and Challenges to Optimising Primary Care Teams' Electronic Health Record Usage." Informatics in Primary Care 21(3): 142-51.

Pare, G., L. Raymond, A.O. de Guinea, P. Poba-Nzaou, M.C. Trudel, J. Marsan et al. 2014. "Barriers to Organizational Adoption of EMR Systems in Family Physician Practices: A Mixed-Methods Study in Canada." International Journal of Medical Informatics 83(8): 548-58.

Paterson, G., N. Shaw, A. Grant, E. Delisle, K. Leonard, S. Mitchell Corley et al. 2011. “Cross-Canada EMR Case Studies: Analysis of Physicians' Perspectives on Benefits and Barriers." Electronic Journal of Health Informatics 6(4): e34.

Payne, T.H., D.W. Bates, E.S. Berner, E.V. Bernstam, H.D. Covvey, M.E. Frisse et al. 2013. "Healthcare Information Technology and Economics." Journal of the American Medical Informatics Association 20(2): 212-17.

Pearce, C., M. Arnold, C. Phillips, S. Trumble and K. Dwan. 2011. "The Patient and the Computer in the Primary Care Consultation." Journal of the American Medical Informatics Association 18(2): 138-42.

Perera, G., A. Holbrook, L. Thabane, G. Foster and D.J. Willison. 2011. "Views on Health Information Sharing and Privacy from Primary Care Practices Using Electronic Medical Records." International Journal of Medical Informatics 80(2): 94-101.

Phoenix Strategic Perspectives Inc. 2013. Final Report Survey of Canadians on Privacy-Related Issues, Prepared for the Office of the Privacy Commissioner of Canada. Ottawa, ON: Phoenix Strategic Perspectives Inc. Retrieved June 6, 2016. <www.priv.gc.ca/information/por-rop/2013/por_2013_01_e.asp>.

Price, M., A. Singer and J. Kim 2013. "Adopting Electronic Medical Records or Just Electronic Paper Records." Canadian Family Physician 59(7): e322-29.

Randhawa, G.K., F. Lau and M. Price. 2013. "Evaluating the Adoption of e-Prescribing in Primary Care." Healthcare Quarterly 16(4): 55-60.

Raymond, L., G. Pare, G.A. de Ortiz, P. Poba-Nzaou, M.C. Trudel, J. Marsan et al. 2015. “Improving Performance in Medical Practices through the Extended Use of Electronic Medical Record Systems: A Survey of Canadian Family Physicians." BMC Medical Informatics and Decision Making 15: 27.

Report of the Advisory Panel on Healthcare Innovation. 2015. Unleashing Innovation: Excellent Healthcare for Canada. Ottawa, ON: Health Canada. Retrieved June 6, 2016. <www.healthycanadians.gc.ca/publications/health-systemsysteme-sante/report-healthcare-innovation-rapport-soins/alt/report-healthcare-innovation-rapport-soins-eng.pdf $>$.

Rich, P. 2015. "Edging Toward the Digital Future: National Physician Survey Findings Reveal Progress - But Also Gaps." Future Practice (March 2015): 3-7.

Rimmer, C., S. Hagens, A. Baldwin and C.J. Anderson 2015. "Measuring Maturity of Use for Electronic Medical Records in British Columbia: The Physician Information Technology Office." Healthcare Quarterly 17(4): 75-80.

Rubinowicz, A., I. Vedel, S. Sanche, M. Lortie, S. Law, J. Hughes et al. 2016. “A Portrait of Electronic Medical Record Use in Primary Care across Canada." Health Reform Observer 4(2): Article 1.

Ryan, M.S., S.C. Shih, C.H. Winther and J.J. Wang. 2014. "Does It Get Easier to Use an EHR? Report from an Urban Regional Extension Center." Journal of General Internal Medicine 29(10): 1341-48.

Schoen, C., R. Osborn, D. Squires, M. Doty, P. Rasmussen, R. Pierson et al. 2012. "A Survey of Primary Care Doctors in Ten Countries Shows Progress in Use of Health Information Technology, Less in Other Areas". Health Affairs (Millwood) 31(12): 2805-16.

Sicotte, C., L. Taylor and R. Tamblyn. 2013. "Predicting the Use of Electronic Prescribing Among Early Adopters in Primary Care." Canadian Family Physician 59: e312-21.

Sittig, D.F. and A. Wright. 2015. "What Makes an EHR 'Open' Or Interoperable?" Journal of the American Medical Informatics Association 22: 1099-101.

Terry, A.L., M. Stewart, M. Fortin, S.T. Wong, M. Kennedy, F. Burge et al. 2014. “Gaps in Primary Healthcare Electronic Medical Record Research and Knowledge: Findings of a Pan-Canadian Study." Healthcare Policy 10(1): 46-59. 
Terry, A.L., J.B. Brown, L.D. Bestard, A. Thind and M. Stewart. 2012. "Perspectives on Electronic Medical Record Implementation after Two Years of Use in Primary Health Care Practice." Journal of the American Board of Family Medicine 25(4): 522-27.

Terry, A.L., G. Giles, J.B. Brown, A. Thind and M. Stewart. 2009. "Adoption of Electronic Medical Records in Family Practice: The Providers' Perspective." Family Medicine 41(7): 248-52.

Unertl, K.M., M.B. Weinger, K.B. Johnson and N.M. Lorenzi. 2009. "Describing and Modeling Workflow and Information Flow in Chronic Disease Care." Journal of the American Medical Informatics Association 16(6): 826-36.

Vedel, I., L. Lapointe, M.T. Lussier, C. Richard, J. Goudreau, L. Lalonde et al. 2012. "Healthcare Professionals' Adoption and Use of a Clinical Information System (CIS) in Primary Care: Insights from the Da Vinci Study." International Journal of Medical Informatics 81(2): 73-87.

Willison, D.J., K. Keshavjee, K. Nair, C. Goldsmith and A. Holbrook. M. 2003. "Patient Consent Preferences for Research Uses of Information in Electronic Medical Records: Interview and Survey Data." BMJ 326(7385): 373.

Willison, D.J., L. Schwartz, J. Abelson, C. Charles, M. Swinton, D. Northrup et al. 2007. "Alternatives to Project-Specific Consent for Access to Personal Information for Health Research: What Is the Opinion of the Canadian Public?" Journal of the American Medical Informatics Association 14(6): 706-12.

Willison, D.J., V. Steeves, C. Charles, L. Schwartz, J. Ranford, G. Agarwal et al. 2009. “Consent for Use of Personal Information for Health Research: Do People with Potentially Stigmatizing Health Conditions and the General Public Differ in Their Opinions?" BMC Medical Ethics 10: 10.

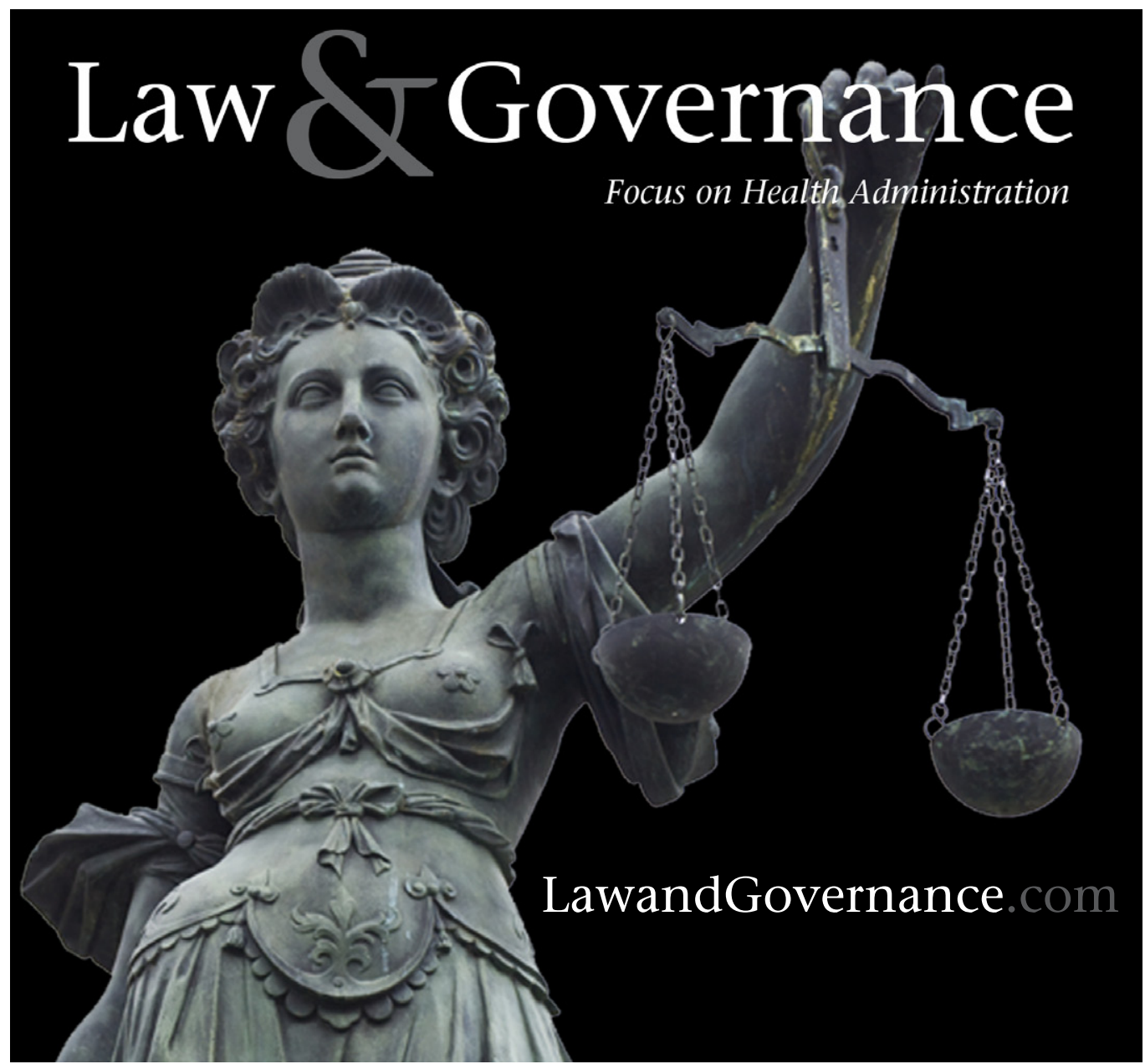

